\title{
Widespread Hotel: An Innovative Made in Italy Model for Cultural Tourism and Local Sustainable Development-The Umbria's Case
}

\author{
Bernardino Quattrociocchi, Marta Maria Montella \\ Sapienza University, Rome, Italy
}

\begin{abstract}
Widespread hotels represent a new Italian phenomenon still not much investigated, both on theoretical and empirical side, which cannot be ignored anymore. Indeed they meet the need to implement techniques and management tools which are able to improve the culture-tourism binomial. This would permit to transform into valid instruments of national economical development, the shared declaration of intents for which culture and tourism, especially in Italy and in this particular fragile period, represent even more the main strategic levers for the sustainable development. This article intends to describe the potentiality of these widespread hotels as innovations particularly suitable with trends recently emerged in tourism sector and outline the phenomenon pattern in Italy with particular attention on Umbria region, in order to identify his main strength and weakness and some innovation to improve performance. To this end, it starts from the analysis of the national and international economic-managerial literature concerning in particular cultural and experienced trends shown in tourism. Then it introduces the main acquisitions about widespread hotels in Italy, updating and extending them through a desk survey based on indirect sources of various natures. Lastly, it describes the case of Umbria, analyzing more in depth making use of interviews with entrepreneurs/managers of hotels and based on a semi-structured questionnaire. The aspects of indeterminateness which were found, starting from the normative one, testify how the potentiality of the widespread hotels as far as regards the value creation for the enterprise itself and the territorial stakeholder, are still not properly understood and therefore used. It is clear that, therefore, new behaviors are needed for entrepreneurs and, most importantly, for local policy makers in order to create the conditions for the full success of these hospitality models.
\end{abstract}

Keywords: tourism, culture, sustainability, Italy, innovation, widespread hotels

\section{Introduction}

In the last decades, the economic, social, and cultural context, especially the Italian one, has been affected by several changes.

Among many consequences of them, particularly important as regards the objectives of the research, is the coming out of new consumer trends, especially in tourism sector. Indeed the search of cultural experiences, which are authentic and unique, is increasing, and therefore the need of a product-offer is not only confined to

Bernardino Quattrociocchi, associate professor, Economics and Business Administration, Sapienza University, Rome, Italy.

Marta Maria Montella, research fellow, Economics and Business Administration, Sapienza University, Rome, Italy.

Correspondence concerning this article should be addressed to Bernardino Quattrociocchi, Department of Management, Sapienza University, Via del Castro Laurenziano 9-00161 Roma, Italy. E-mail: bernardino.quattrociocchi@uniroma1.it. 
the traditional cities of art, but that leads to the discovery of little places, focusing on the communication and the organisation of the resources of the territory in a widespread organizationally and culturally holistic perspective. The tourist offer must therefore integrate museums, old towns, landscapes, food and wine and every other material and immaterial evidence of the territory culture. Meanwhile, tourists are developing a responsible behaviour according to the urgent need of implementing models of sustainable development also in this sector. New solutions are necessary in order to redistribute in time and space touristic flows and to avoid the economic, social, and environmental negative effects due to their concentrating in limited periods of the year and in few particularly famous places.

Furthermore, the development of the cultural resources which qualify and testify the identity of a territory became the base for policies and territorial marketing actions, according to the increasing trend of creating models of economic development on a base of a value-driven or value-based planning. So with the rising of the competitiveness among geographical contexts, the cultural heritage is recognised as one of the possible levers of the development and socio-economic cohesion strategy and, therefore, as a crucial resource of the local development process.

This, of course, has a greater importance in our country, whose competitive advantage is to have a cultural heritage rich in quality and quantity, but which is distributed in the whole country and consists of a various nature: museums, monuments, old towns, artistic, architectural and archaeological heritage, food and wine, landscape, traditions, festivals, knowledge, abilities and so on. The enterprises of the tourism sector in order to be competitive and to survive should therefore adapt their dynamic development to the new context. If taking a look to the Italian hotel sector, among the recent implemented innovations, the widespread hotels are particularly effective. Those entrepreneurial realities, which spread in Italy in the last decades and nowadays are over a hundred, as a matter of fact, are particularly relevant both in intercepting the multiple utilities which move the principal cluster of tourist and valorising suburb areas as much as the traditional mass circuit, which has a great cultural value, thus contributing in a sustainable development.

This recent phenomenon absolutely made in Italy and worldwide admired (Williams, 2010; Murphy, 2011) cannot be overloaded anymore neither by economic-managerial literature, nor by local and national public representatives and tourism legislation. Despite the increasingly widespread of good business practices and the lively debate on this subject, it can be found that many aspects of vagueness in this regarding obstruct the creation and the widespread of the entire possible value for the enterprise itself and for the local stakeholder ${ }^{1}$ and witness how the potentialities of these hotels are not yet understood and valorised.

The aim of this article is therefore to describe the potentialities of the model of widespread accommodation as an innovative and strategic solution, as it is very suitable for the new tourism realities and the paradigm of sustainability, and to outline a synthetic picture of the current spread of the phenomenon in Italy, focusing on Umbria region. This paper intends to identify strength and weakness of the investigated realities and give some innovations to improve performances.

First there will be a reference to the principal thesis processed by national and international economic-managerial literature of the tourism sector, as a theoretical and conceptual framework of reference with particular intention to the experience, cultural, and sustainability.

\footnotetext{
${ }^{1}$ Utilities provided by the widespread hotels for the surrounding context (starting by the social body and the economic traders) represent substantial internalities for the enterprise, helping to strengthen its relation capital and fame and obtaining diffused consent and legitimation.
} 
Then this paper will have a look to the main features of Italian widespread hotels. As empirical evidence of the research hypothesis, they will be introduced with the results of the data about widespread hotels in Umbria - an appreciated touristic destination for its cultural heritage and particularly dynamic region in regard of the investigated phenomenon. The investigated hotels, thanks to the good practises applied, are examples of the general Italian situation (Paniccia, Silvestrelli, M. M. Montella, Rozera, \& Valeri, 2013) and permit to focalise on the strength of those entrepreneurial solutions and also the weakness, in order to identify strategies and policies able to optimise the performances.

The object is to contribute to this subject, which is still not much investigated both theoretically and empirically, if considering its recent spread and giving useful and practical suggestions to the entrepreneurs of the tourism sector and the local policy maker, whose responsibility is to define the context conditions which can support the full realisation of these tourism models and the results optimisation. Public representatives, whose institutional responsibility is an effective destination management, should indeed better understand the value of the local development of widespread hotels.

\section{Nowadays Tourism Trends}

In the last years, tourism has quantitatively and qualitatively deeply changed. It follows the evolution of the users' features according to the consumer post-modern paradigm. This has emerged as a result of the context changes occurred in Italy since 1960s, ending with the fulfilment of primary needs, the extension to the entire social body of desires once reserved to aristocracy and involving, regarding consumption, a phenomenon of democratization.

The new consumer is wealthier, educated and with more spare-time consciously and individually to choose, making the demand heterogeneous and multiform. Being more exigent and able to affect the demand, he puts himself as prosumer in a value co-creation aspect. More and more influenced by the offer starting from the symbolic, cultural and aesthetic qualities, the consumer looks for fun and the anti-homeostatic subversive pleasure of the utility concept, giving more importance to the experience side.

In the tourism sector, the search of real and unique experiences which is also involved with senses and imagination plays a primary role (Carù \& Cova, 2007). Moreover, the acknowledgement of the human capital as a condition to live satisfying experiences and to raise personal condition gives the increasing importance to cultural consumption. Before they were just a privilege for educated elites with a personal and usually also economic capital above average, they result in a dimension of mass, becoming an essential part of the standard package of several social groups. The cultural consumptions, essential for the life-quality and included among citizenship rights (Art. 3 and 9 Cost. and Universal Declaration of Human Rights of 1948), become the main determinant of tourists choice. Moreover, it is growing the attention on ethical behaviour of producers and consumers that are brought to act consciously and responsibly towards the environment, society, and wealth distribution.

\section{Cultural Tourism}

Cultural tourism (Boniface, 2013; Smith \& Richards, 2013) that started to spread around 1970s as a result of the rapid economic, social, and cultural development, and of the consequent increase of spare time (Atchison, MacLeod, \& Shaw, 2014) and occurred in almost all western industrialised countries, registered in the last two decades great changes. The demand has been distinguished and characterised by instances of authenticity and 
of multidimensional and multi-thematic experience (Ferrari \& Veltri, 2008), showing an interest in the understanding of the culture of the places through their several evidences (Franch, Martini, Buffa, \& Parisi, 2008; Organization for Economic Cooperation and Development, 2009; Golinelli, 2012; Ashwort \& Larkham, 2013; Kavaratzis \& Hatch, 2013). Tourism is looking for alternative destinations compared to the traditional mass destinations and a complex product-composite offer: museums, old towns, exhibitions, nature, and typical products (Ringer, 2013). The understanding of distinctive identity of places (Boisen, Terlouw, \& Van Gorp, 2011) is indeed possible through the material and immaterial cultural heritage, including the tacit knowledge locally sedimented, which is important for the local development (Raagmaa, 2002; Throsby, 2005; Santagata, 2006; Denicolai, Cioccarelli, \& Zucchella, 2010).

These changes are affected by the new concepts of culture, cultural heritage, and territory that are famous in Italy on those years (M. M. Montella, 2012). The notion of culture has assumed a systemic setting of a wide anthropological meaning and special extent, thereby overlapping with the concept of civilisation. Hence the coming out of the concept of cultural heritage is taken as every material evidence that has a civilisation value. At the same time, the territory is considered as environment ${ }^{2}$ and then landscape. As a complex system of unique cultural resource generated by the secular succession of civilisation, highly identified and differentiating, it is therefore considered as a visible form-evidence of history (Baker \& Cameron, 2008). This leads us to recognise the primary value of the context: The anthropic landscapes are included in the human heritage and the European Landscape Convention is stipulated and absorbed by the Italian legislation (D. leg. 42/04, Art. 131). ${ }^{3}$

To make new cultural-tourism trends optimally suit Italy, one of the top destination in the world, this, in fact, with a widely diffused heritage and therefore absolutely contextualised, permits to follow the path distributed throughout the country for the benefit of smaller and suburban towns. It's precisely the territorial continuity of the cultural phenomenon, not compromised as elsewhere by the great political or industrial revolutions, that constitutes, therefore, the Italian privilege that allows to achieve competitive advantages sustainable in long terms.

In the light of all these, cultural tourism turns out to be essential to increase number and staying times of tourists in a place and to reach a sustainable tourist development (Girard \& Nijkamp, 2009).

The presentation of territory resources in a widespread organizational and culturally holistic respective contributes in fact to the temporal and spatial distribution of the flows, avoiding excessive crowds that exceed the physical and cultural load capacity of the places and the individual attractors that insist on it, as well as the efficiency threshold of the services of the different species.

A proof of the growing importance of cultural segment is the positive trend registered by it in view of decreases in other sectors of tourism, becoming an important national and local economic lever and fully qualifying itself as productive sector ${ }^{4}$ (Mckercher \& Du Cros, 2002; De Carlo \& Dubini, 2010; National Tourism Observatory [ONT], 2013). In 2011, Italy is first in the ranking of Country Brand Index for attractiveness linked to the culture and cities of historical-artistic interest excel among various types of locations for attracting tourists (ISTAT). These locations which compared to 2007 incomings $(+10 \%)$ and

\footnotetext{
2 It is as with systemic ecological values and therefore also social and cultural values economically relevant (milieu).

${ }^{3}$ Here it is stated that the landscape, extraordinary or deteriorated, cooperates in the processing of local cultures and is a key-component of the cultural and natural heritage of Europe, thus contributing to the welfare and satisfaction of human beings and the consolidation of European identity.

${ }^{4}$ In Italy, state-owned heritage is estimated around $120 \%$ of GPD.
} 
attendances $(+14 \%)$ have grown, receive the $36 \%$ of total national arrivals and the $25 \%$ presences, with a majority of foreigners (59\% of arrivals, $61 \%$ of attendances) (Figure 1). Since the daily impact of a cultural tourist (direct and indirect effects included) triples that of a traditional visitor (400 Euros vs. 130) according to ONT, the value of cultural tourism exceeds 40 billion in 2011. This amount takes into account the tourism flows only in the historical-artistic cities, while the cultural tourism represents all those flows of people with cultural purposes, for example, study holidays, the attendance at live shows, festivals, cultural events, visit to archaeological sites and monuments, and pilgrimages, and concerns also the pleasure of being part of local lifestyle in its identity and character (ONT).

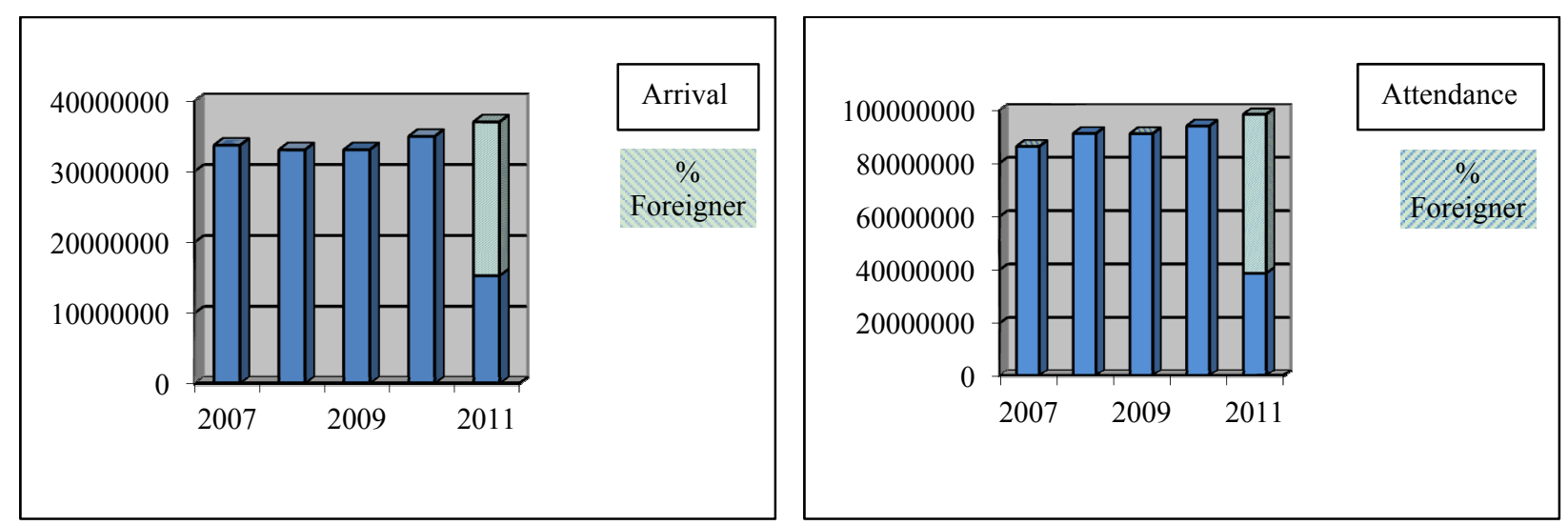

Figures 1. Arrivals and attendances in Italian cities of historical and artistic interest (2007-2011) and \% of foreigners (2011).

Regarding to the offering, in 2010 the art cities are the second place in Italy, along with the mountain resorts, with the largest number of accommodation establishments and beds (17\%), exceeded only by the seaside resorts (33.5\%) (Figure 2). Among those cities in 2012, Rome offers the greatest numbers of accommodations $(149,942)$, followed by Venice $(118,168)$, Milan $(57,884)$, and Florence $(41,914)$.

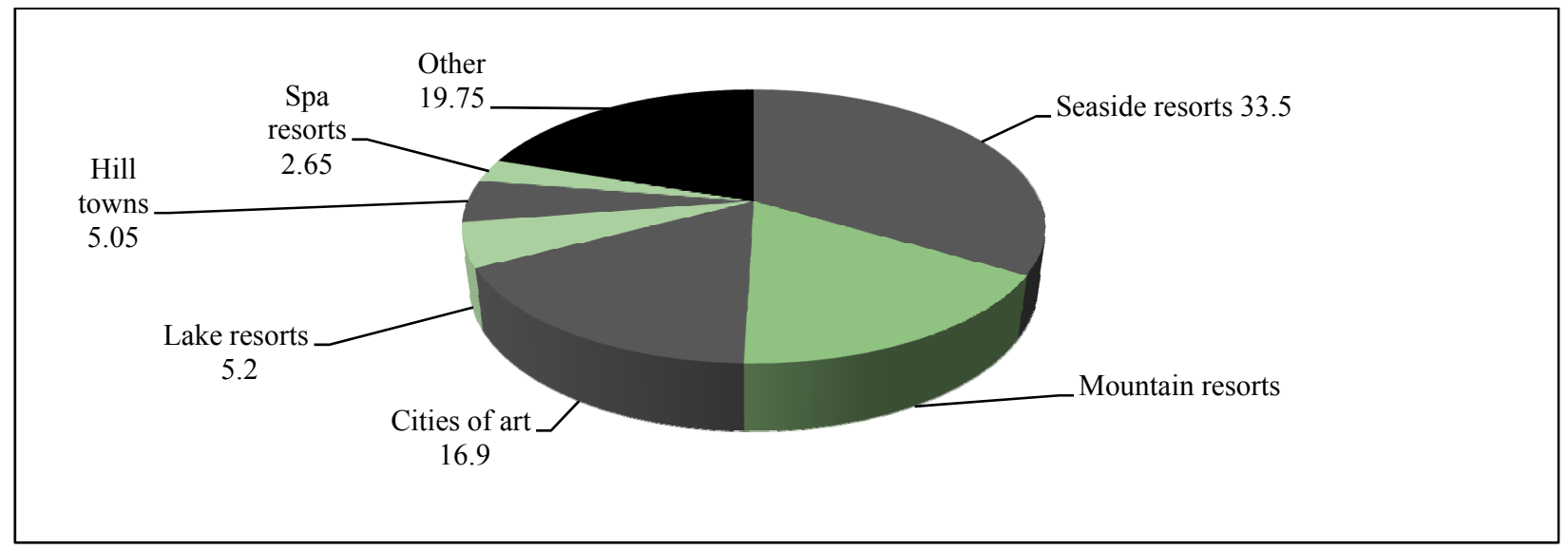

Figure 2. Concentration of tourist accommodation in Italy (2010).

\section{Sustainable Tourism}

In recent years, the demand for conscious and responsible behavior towards the environment, society and the distribution of wealth has also affected the tourism sector, influencing consumers behavior and business models (Gössling, Hall, \& Weaver, 2009; Bramwell \& Lane, 2011; Buckley, 2012; Waligo, Clarke, \& Hawkins 2013). 
In fact, tourism, as a multidimensional phenomenon, plays a vital role in sustainable development, to be coherent with future and present needs (Burton, 1987). It is necessary to avoid excessive crowds that exceed the carrying capacity of supporting ecosystems on which it depends.

This means to avoid the territory depletion, without compromising the environment quality, not changing the social and cultural balance, not producing costs that cannot be covered through the revenues for the facilities and infrastructures, nor carrying consumptions (energy, water, and landscape) higher than acceptable.

In order to achieve the objective of sustainability, balancing the economic benefits with the social and eco-environmental ${ }^{5}$ ones, tourism enterprises should implement innovations on the one hand, such as strategic drivers of business competitiveness and profitability, as well as benefits for the stakeholder (economic efficiency), and on the other hand operate in respect of individuals and entire social body by satisfying their needs and expectations (social efficiency), as well as the environment ones, starting from the use of resources ( environmental efficiency).

Tourism would then be a determining factor for the development of the local system.

To all, it would be useful to include the management of tourism activity in a process of territorial planning (Ahn, Lee, \& Shafer, 2002). Rather than be limited to traditional approaches and tools (for example, public-private partnership), it would implement a systemic governance of the territory (Beritelli, 2011; Bramwell \& Lane, 2011; Scuttari, Lucia, \& Martini, 2013), based on the cooperation among local actors (public administration, tourism, culture, gastronomy, crafts, etc.) and between them and the local community, as well as on decision-making processes based on consultation and participation of stakeholders. From this structure, a strong support for innovation and a strategic contribution to the competitiveness of tourist destinations can be expected (Mazanec, Woeber, \& Zins, 2007; Crang, 2014).

To the sustainable tourism, development of territories also contributes a lot to the integrated enhancement of cultural heritage in the places, facilitating temporal and spatial distribution of the flows and revitalizing suburban areas. The increase in demand for goods and services generated by these actions will effectively determine additional remunerations, support the mitigation of demographic landslide that often dries up the suburban areas, and contribute to the local heritage protection (Quattrociocchi, Faggioni, \& M. M. Montella, 2012).

\section{A Made-in-Italy Format Innovation}

To remain responsive to the context described so far, tourism enterprises should adapt their business model renewing the range of offered products, methods of production, supply and distribution (technological innovation), the management, the organization, working conditions and skills (organizational innovation) (European Commission, 2004).

Among the new forms of tourism offer is particularly the interest of hospitality service and especially are those based on the renewed perception of the territory as a landscape. Among them stand the widespread hotels.

\footnotetext{
5 Today within EU-27, tourists consumption exceeds 5\% of GPD and the economics of travel and tourism (which also includes the goods and services related to tourism) are worth at least $10 \%$ of GPD. Employment in the sector of receptivity is equal to 2.3 million of people, while that one of the tourism industry is estimated between 12 and 14 million (European Commission -Directorate General for Enterprises and Tourism). Wide is also its ability to contribute to the welfare and quality of life of both tourists, as a form of fun and learning, and host community, as the primary factor for the development of territories and for any need for revitalization.
} 
The innovation of these business solutions can be found both in structure and in management methodologies. Based on the idea of widespread hospitality developed in Italy in the late 1970s to enhance the villages affected by the earthquake in Friuli, these business solutions outstand for (Droli \& Dall'Ara, 2012):

- providing accommodation in separate buildings next to each other and the buildings that offer services of reception and concierge (D.Lgs. 79/2011, Art.9), assuming a horizontal configuration and dividing in more housing units;

- being used for the production and delivery of the service existing buildings and part of the culture of the place;

- preferring places outside the traditional circuits of mass.

Depending on the nature of the buildings in which they articulate, it is possible to divide them into three main types (Paniccia et al., 2013):

- hotels in historic village;

- hotels in old rural farmhouse;

- hotels in antique residence.

The widespread hotels, unlike what usually happens to the traditional ones, are deeply linked to the socio-cultural and natural context and recognize the local cultural heritage (in its widest sense, also inclusive of environmental and social resources) as primary resource of the development project, strategic asset on which leverages in order to differentiate their offerings, capture the tourist demand, and achieve high levels of customer satisfaction. This intimate connection is also evidence of the important socio-cultural role, as well as economic, recognized by widespread hotels to catering, enhancement tool of products and local culinary traditions and, therefore, the territory itself. The traditional food, in fact, is a very important cultural evidence, as related to the distinguishing characteristics, tangible and intangible, of a place and its history: living environment, system of values, customs, physical environment, knowledge and skills of the community in different places and times (Altili, 2010; M. Montella, 2012). Moreover, these hotels as well as promote local products, wine and craft, often have small libraries and museums dedicated to the area and offer information on local cultural heritage (history, art, nature, etc.). In addition to this, the requalification of buildings of local tradition, absolutely authentic and rooted in the context, conducts respecting the identity of the original architecture and furnishings, makes these hotels part of a story that continues in the surrounding area, offering to the tourist the intimate dimension of the little village and its cultural heritage. Travelers have the opportunity in this way to live as temporary residents of the place, soaking in the atmosphere and culture of the place and integrating themselves with the local community and customs. This allows them to experience unforgettable, authentic, and unique experiences that invest mind, senses, and imagination.

This attitude, as a critical factor of success of such hotels, takes advantage of the Italian privilege which leverages in order to achieve sustainable competitive advantages in the long run, consisting in the inclusion of a cultural heritage not limited to the cities of art, but widespread throughout the country and, therefore, extended to smaller and suburban towns. This explains the Italian origin of this model of hospitality, which is characterized as a phenomenon made in Italy and admired in the world (Williams, 2010; Murphy, 2011).

The widespread hotels also help to distribute tourist flows in time and space, and particularly suit to the paradigm of sustainability acting as drivers for the development of a territory and the development of the entire socio-economic, local, and national system. 


\section{Description of the Phenomenon}

The phenomenon of widespread hotels is still not much investigated by the economic-managerial literature both on theoretical and empirical side, and is not adequately considered by local decision makers.

It seems therefore appropriate to draw a concise picture of the spread and the main characters of the widespread hotels in Italy (number; localization; types-segmentation criteria and consistency; dimensions - housing units, rooms, and occupied beds) updating and extending the investigations conducted on the topic in recent years (Paniccia et al., 2013; Silvestrelli, 2012). To this end, a desk survey, based on indirect sources of various natures, has been conducted:

- scientific publications and articles of national and international newspapers;

- websites of hotel companies, institutions, category associations and co-ordination structures (for example, National Association of Widespread Hotels, Association Authentic Villages of Italy, etc.);

- operators of regional and local authorities and representatives of local and national tourism organizations (for example, CCIAA, tourist Offices, IAT, and Pro Loco);

- national and regional tourism regulations.

Based on the achieved results, authors chose to analyze the case of the widespread hotels in Umbria in more detail, whose results are particularly interesting with respect to the research objectives and significant of this type of accommodation as:

- numerically significant;

- young entrepreneurial realities of success strongly guided by the principles of sustainability;

- located in a region with a vast and various cultural heritage, very popular among tourists eager to experience the culture of minor places and particularly dynamic regarding the phenomenon investigated.

The survey wants to contextualize these realities in the region tourism context and describe its main characters, also to check whether they represent a format innovation consonant with the main determinants of tourism choices and with the policy of sustainable development and to identify the major obstacles to the achievement of the entire possible value. From the universe of widespread hotels in Umbria was excluded a too new structure. For the survey, in addition to indirect sources mentioned above, authors made use of interviews with entrepreneurs/managers of hotels based on a semi-structured questionnaire. This, elaborated to combine the objectives of the research with the possibility to compare the data with those of surveys conducted on other Italian cases (Paniccia et al., 2013), is divided into nine sections:

(1) establishment of the enterprise;

(2) offered services;

(3) dimensions;

(4) occupied;

(5) tourism flows;

(6) promotion;

(7) environmental efficiency;

(8) social efficiency;

(9) economic efficiency.

They are dominated by closed questions (54\%), which are presented in the form as dichotomous (yes/no; $22 \%$ ) and as verbal scales like Lickert (1: not at all; 2: a little; 3: enough; 4: much; 5: very much; 13\%). 


\section{National Framework}

This formula of hospitality, recognized in Italy for the first time at the end of the 20th century from Sardinia Region, is very successful especially among tourists at the discovery of minor Italy, so much so that in 2011 the Touring Club dedicated a guide to it.

At the end of the first quarter of 2014 , there are 89 widespread hotels ${ }^{6}$, located in all regions except the Valle d'Aosta and concentrated in the south and central ones (Table 1).

Table 1

Italian Widespread Hotels: Geographical Distribution (March 2014)

\begin{tabular}{|c|c|c|c|c|c|}
\hline \multirow{2}{*}{ Areas } & \multicolumn{2}{|r|}{ Included regions } & \multicolumn{2}{|c|}{ Widespread hotels found } & \multirow{2}{*}{$\begin{array}{c}\text { Average of widespread } \\
\text { hotels by region }\end{array}$} \\
\hline & $\begin{array}{l}\text { Absolute } \\
\text { value }\end{array}$ & $\begin{array}{l}\% \text { of the total number of } \\
\text { regions with widespread hotels }\end{array}$ & Absolute value & $\%$ of the national total & \\
\hline Northern Italy & $7 *$ & $37 \%$ & 16 & $18 \%$ & 2 \\
\hline Central Italy & $4 * *$ & $21 \%$ & 33 & $37 \%$ & 8.5 \\
\hline Southern Italy & $8 * * *$ & $42 \%$ & 640 & $45 \%$ & 5 \\
\hline
\end{tabular}

Notes. * Trentino Alto Adige, Veneto, Lombardia, Piemonte, Liguria, Friuli Venezia Giulia, and Emilia Romagna; ** Tuscany, Umbria, Lazio, and Marche; *** Abruzzo, Molise, Campania, Puglia, Basilicata, Calabria, Sicily, and Sardinia.

Particularly dynamic are Lazio (10\%), Umbria, Tuscany, Marche, Molise and Sardinia (9\%) (Figure 3).

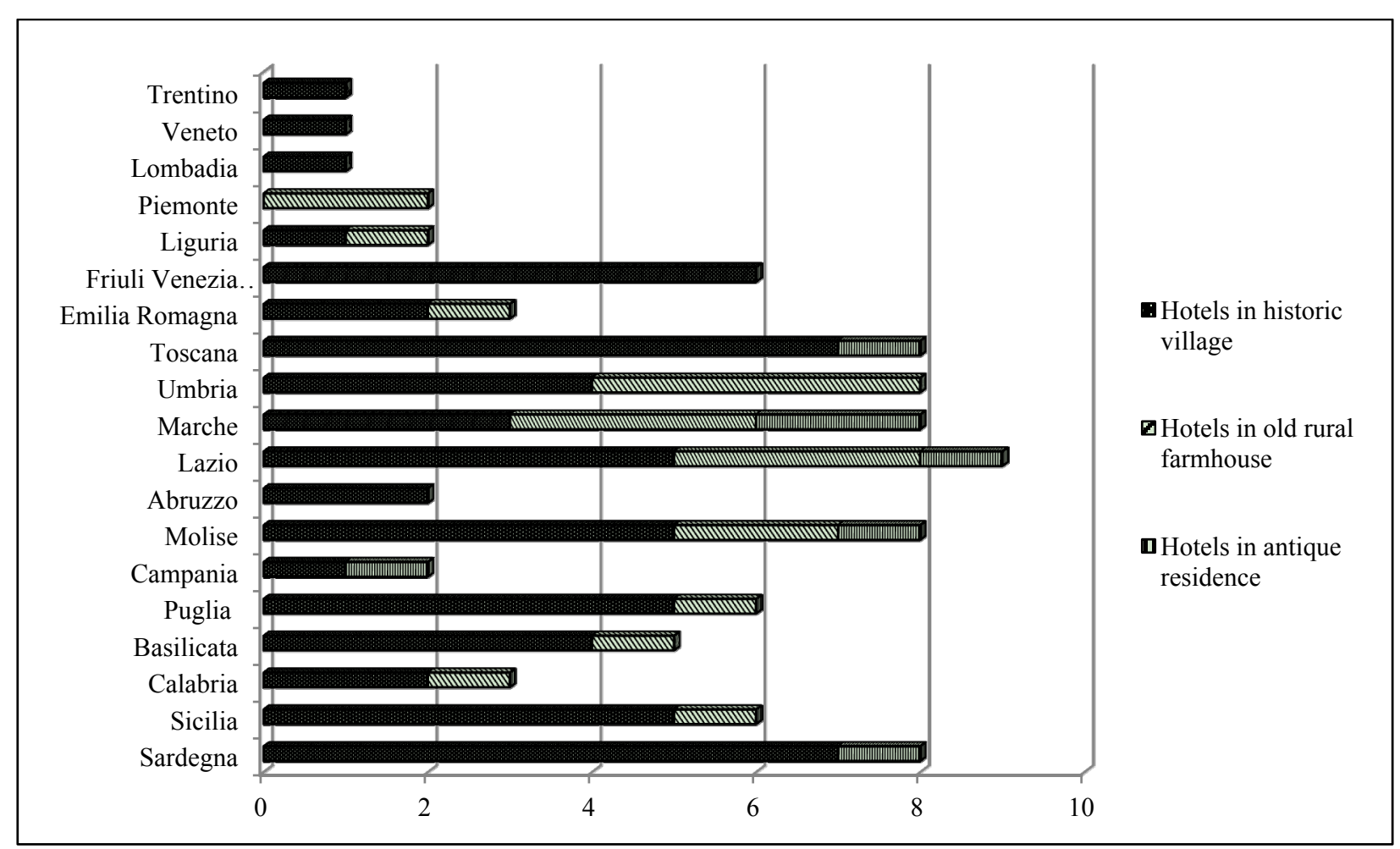

Figure 3. Italian widespread hotels: Distribution by regions and types (March 2014).

They can be found in small size areas $(<5,000$ inhabitants) and have national awards $(53 \%)$ of environmental type (Italy's authentic villages: $9 \%$; most beautiful village of Italy: 10\%; orange flag of Italy

\footnotetext{
${ }^{6}$ Mapping the universe of Italian hotels doesn't purport to be complete.
} 
Touring Club: $11 \%$; agriculture green flag: $1 \%$; blue flag: $1 \%$; alpine pearls: $1 \%$; UNESCO: $6 \%$; cities of art: $1 \%^{7}$ ) and/or productive type (cities of the oil: $9 \%$; cities of ceramic: $1 \%$ ). Hotels in the historic village predominate $(70 \%)$, followed by those in old rural farmhouse $(22 \%)$ and manor $(8 \%)$. This trend also occurred in the North, Central, and Southern (Table 2 and 3).

Table 2

Italian Widespread Hotels: Distribution by Types and Geographical Areas (March 2014)

\begin{tabular}{lllll}
\hline Areas & Hotels in historic villages & Hotels in rural residences & Hotels in manors & Total \\
\hline Northern Italy & 12 & 4 & 0 & 16 \\
Central Italy & 19 & 10 & 4 & 33 \\
Southern Italy & 31 & 6 & 3 & 40 \\
Italy & 62 & 20 & 7 & 89 \\
\hline
\end{tabular}

On average, they consist of eight units, 17 rooms, and 41 beds and employ five people. Widespread hotels in historic villages are larger (Table 3).

Table 3

Average Sizes of Italian Widespread Hotels: Whole Universe vs. Individual Types (31/03/2014)

\begin{tabular}{lllll}
\hline & Unite & Rooms & Beds & Occupied \\
\hline Widespread hotels & 8 & 17 & 41 & 5 \\
Hotels in historic villages & 11 & 19 & 46 & 5 \\
Hotels in old rural residences & 4 & 14 & 34 & 5 \\
Hotels in manors & 3 & 9 & 23 & 3 \\
\hline
\end{tabular}

\section{Umbria Case}

Umbria, located in the heart of Italy between Tuscany and Lazio, presents rivers (for example the Tiber), lakes (Trasimeno, Piediluco), waterfalls (Le Marmore), green hills, cities of art (Perugia, Assisi, Orvieto, Spoleto, ...) and settlements rich in history and traditions, as already inhabited in prehistoric times (Umbrian and Etruscan) and then part of Roman Empire and the Papal States, as well as important transition zone between the Adriatic and the Tyrrhenian Sea. It extends for 8,456 sq. km. (Perugia: 6,334; Terni: 2,122) and has a population of 886,239 inhabitants (PG: 657,873; TR: 228,366). Most of its towns are very small or medium-small $\left(66.3 \%<5,000\right.$ inhabitants; $5,000<21.7 \%>20,000$ inhabitants $\left.^{8}\right)$. As far as regard, accommodations, the hotels, area of interest of this study in 2011 are 574 (13.4\% of the total accommodation), with a total of 29,468 beds ( $32.3 \%$ of the total), 15,016 rooms ( $41.9 \%$ of the total), 15,568 toilets $(43.4 \%$ of the total); 154,618 arrivals are registered $(69.7 \%$ of the total) with a slight predominance of Italians (56.5\%), $3,198,689$ presences ( $52.2 \%$ of the total; average length of stay of 2.1 nights, compared to the $2.8 \%$ of the total) and a room occupancy rate of $31.5 \%$ (compared to $20.8 \%$ of total).

\footnotetext{
${ }^{7}$ For example, the orange flag is the brand of environmental-tourism quality of the Italian Touring Club aimed at small inland towns that stand out for the enhancement of cultural heritage, environmental protection, culture of hospitality, usability of resources, quality of accommodation, food and local products. The brand, with the aim of supporting sustainable development of tourism, promotes the knowledge of little-known places but of great value and encourages travelers to visit them in full compliance with the local environment. The National Association City of Oil gather towns with oil of olives vocation and aims to spread the culture of the olive tree, olive oil of quality, to protect and promote the environment and the landscape of the places of production and to enhance designation of origins, recognizing the key role of this production in the tradition of agriculture, food and culture, strengthening local identity and local entrepreneurship.

$812 \%>20,000$.
} 
Umbria is second in Italy for number of widespread hotels (eight), following Lazio (nine) at a short distance.

Investigated hotels mostly belong to towns of Perugia's province (71.4\%), with an average of $99 \mathrm{sq} \mathrm{km}$ of extension, 8,568 inhabitants (National Institute of Statistics-ISTAT, 01/2013), 90,788 arrivals, 216,492 presences $^{9}$ (length of stay: four nights), 136 accommodations (2011), and national awards (75\%) (cities of oil: $50 \%$; most beautiful village of Italy, UNESCO; slow cities; cities of ceramic: $12.5 \%$ ).

They were born in the first decade of the 21 st century ( $57 \%$, of which $75 \%$ consist of hotels in villages) and in the previous ( $43 \%$, of which $66 \%$ are rural) mostly as LTD (57\%; individual firm: $29 \%$; $14 \%$ : S.A.S.), in order to enhance areas outside the circuit of mass (historic villages: $57 \%$; rural areas: $43 \%$ ), but of a deep historical and cultural interest. For this, they preserved architecture, traditions, and atmosphere of the places where they are located, proving its culture even today.

The conversion of existing buildings for tourism objectives has required considerable interventions conducted in order to combine the preservation of the original characters with high quality accommodation. The hotels, horizontally configured, include an average of six units, 11 rooms, 32 beds, and 13 toilets, as well as rooms for events, swimming pool, parking area, garden for recreational activities. They often feature large farms averaging 15 hectares (43\%), rare riding schools (14\%), spa, volleyball, tennis and archery.

In addition to offering accommodation, breakfast, and restaurant service $(100 \%)$, they organize excursions in the $\operatorname{area}^{10}(86 \%)$, educational activities $(86 \%)$, and events $(75 \%)$.

In the process of production-delivery of the service, on average six people are involved.

In 2011, hotels observed showed an average of 790 arrivals, 2,040 presences, and 2.6 nights stay (Table 4) and a room occupancy rate of $28 \%$; Italian customers (86.5\%) and couples (79.5\%) prevail; the average age is 37 years.

The promotion of the structures is mainly entrusted to the Internet: corporate website, ADI, websites dedicated to the heritage and accommodation offer of the area, in addition to tour operator and the word-of -mouth.

The reviews left in the main websites of the sector on the investigated hotels attest the high levels of customer satisfaction (till $05 / 07 / 2014$, trip advisor-vote $4.3 / 5$ and reviews 945 ; booking-vote $8.8 / 10$ and reviews 117) (Figure 4), determined by housing, staff, food, and location.

Umbrian investigated hotels meet the three requirements of sustainability ${ }^{11}$. For the protection and enhancement of the area, in addition to restoring buildings and participate in associations of tourism promotion, everybody considers the utmost importance to provide a gastronomic offer characterized by local and often organic products (5/5), as well as implement water and energy saving (4.7/5) (special bulbs: 4.7/5; waste control: $\left.4.3 / 5^{12}\right)$; very important is the promotion of naturalistic, artistic, and gastronomic itineraries (4.4/5) (environmental efficiency). These also revitalize the place where they are. Taking dependants from the territory

9 Removing the data from the town of Assisi, absolutely not comparable to the others, the average values per towns decrease to 14,740 arrivals, 61,534 presences, and 86 structures.

${ }^{10}$ For example, Holiday House Borgo Badia organizes a wine school in the vineyards and in the cellars of the estate; Torre della Botonda offers experiential weekends as for example the bike-tour in the streets of Olio and Sagrantino, with visits and tastings in villages, mills and vineries; visits to Marmore waterfalls; underground tours to Narni and Orvieto; both offer jeep tour in the countryside.

${ }^{11}$ Not being able to run out on only one occasion such as a broad subject, it has been decided to prioritize, among many ways to support the positive relationship between this form of hospitality and the pursuit of sustainable goals by individuals who realize it; those considered by previous studies devoted to the phenomenon (Paniccia et al., 2013).

${ }^{12}$ Quite important is given to verify the efficiency of boilers (3.1/5) and the use of ecological detergents (3/5); little importance is given to waste disposal (2.5) and transportation services to low-impact (5.2) and even less noise reduction (5.1), activities impractical or unnecessary. 
(4.4/5) and promoting local typical products (5/5), they show the statement of significance of the place (historical-artistic and architectural products, food and wine, craft and industrial products; traditions, folk festivals, etc.) to residents, reinforcing the community identity, causing them to take care of the local heritage (Quattrociocchi et al., 2012) and contributing, thus, to the mitigation of demographic landslide that often dries up peripheral areas as these ones (social efficiency). In line with this is the positive trend of the population of the towns considered in the affirmation of the hotel business to 2012 ( $+4 \%$ on average; Italian towns). Finally they contribute to the increase in local production and business activities (4.3/5) both related to direct market of the hotel (employment, provision of goods and services), that derive utility from the increase in demand for goods or services generated by this (transports, business activities, catering, farming, craft, culture, tourism, etc.). Among the more, the use of local products in the hotels (wine and food, crafts) claims the producers of goods conveyed under a territorial brand, both immediate and opening a virtuous economic cycle: tourists, once-returned home, potentially continuing to ask for the products appreciated during the holiday, with considerable benefit to the local economy and for the local and for national branding itself (economic efficiency). From that, authors can expect an increase in the differential income for the entire system of economic productivity that results in processes of consumption, reverberating its positive effects on the entire local economy. Consistent with this, in the investigated towns, the per capita income of the population was recorded by the opening of each activity to 2012 , an average increase was estimated at $28 \%$, and the income per taxpayer in 2009 almost equaled the regional one (average values of the seven towns: $19.282 €$; Umbria: 19.310 $€)$.

Table 4

Compared Tourist Flows: Umbrian Widespread Hotels vs. Accommodations of its Towns and of the Region (Average Values Per Year 2011)

\begin{tabular}{llll}
\hline & Arrivals & Attendances & Stay \\
\hline Accommodations in the region & 517 & 10,427 & 2.8 \\
Accommodations in investigated towns* & 665 & 2,660 & 4 \\
Widespread hotels in investigated towns & 790 & 2,040 & 2.6 \\
\hline
\end{tabular}

Note. * Removing the data from the town of Assisi comes down to 171.4 arrivals and 658.5 presences.

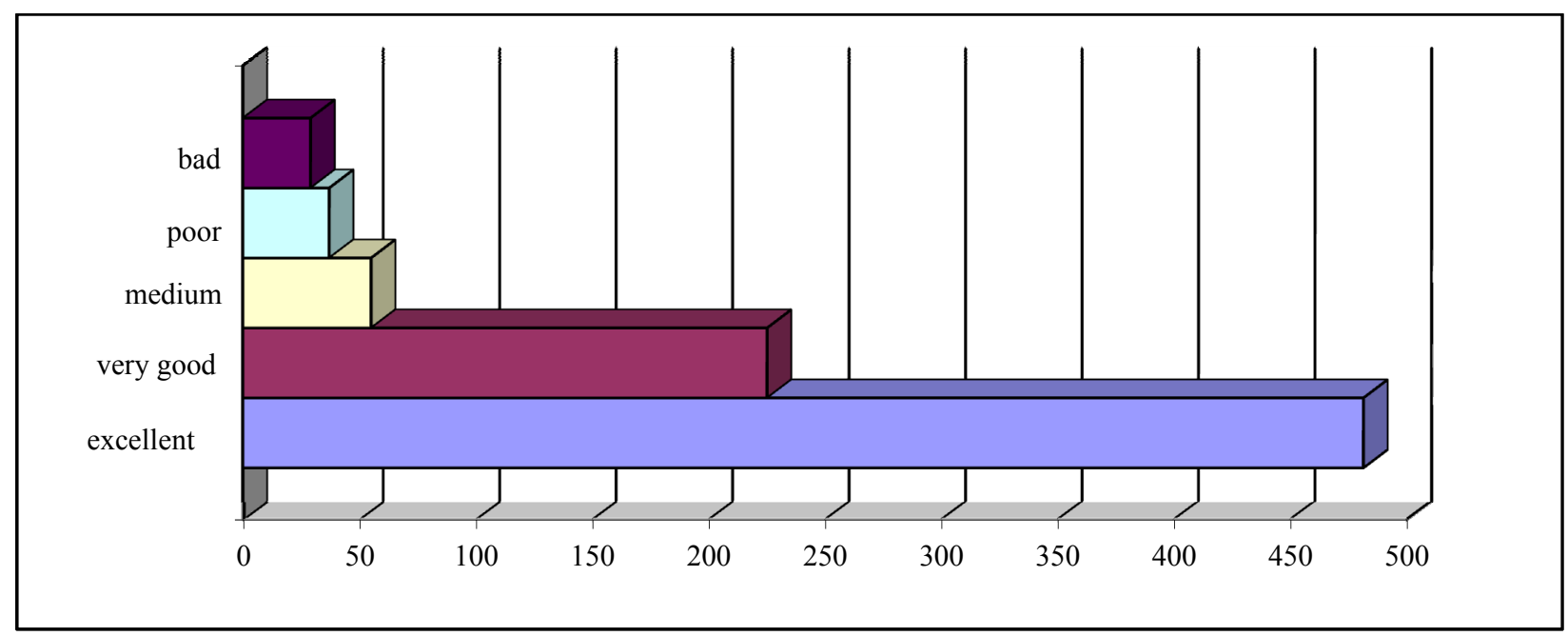

Figure 4. Rating Umbrian widespread hotels. 


\section{Results}

The resulting data show that investigated hotels exemplify the innovative observed model, both in structure and management methodologies. Articulating horizontally in housing units created in existing buildings, part of the culture of the place, they prove to base their competitive advantage on the deep integration with the region and the enhancement of its specific resources (historical, artistic and architectural, landscape, food and wine, crafts, etc.). They are therefore very suited to the paradigm of sustainability and the trends emerged in the tourism sector, offering to tourists the chance to explore unusual, authentic, and valuable destinations, and to become part of the local community and live experiences that involve mind and senses.

Despite these positive aspects, they do not show the ability to take full advantages of the opportunities offered by proximity to centers with considerable tourist inflows (Perugia, Assisi, etc.) and the rapid spread of user segments more and more responsible and attracted to smaller places. Crucial point in this regard would be the strengthening of the regulation of tourism development, in terms of management measures of the impact of the flows, and the promotion of tourism development of suburban areas, and incentives to improve the quality of these new hotels. Decision makers, institutionally responsible for the promotion of local development, should in fact do their utmost for an effective local marketing and to support all the productive and commercial local actors. Regional legislation in force (L.R. 18/2006, Art. 22, 23, 27, 60) is limited to give the widespread hotels a definition in line with the national one and establish the minimum requirements for the granting of permits (numbers of stars, director's tasks, equipment, etc.). It would be decisive, in addition to the strengthening entrepreneurial culture in peripheral locations, the implementation of territorial marketing actions in a systemic way, involving local touristic and cultural actors and integrating themselves into the corresponding demand system of provincial and regional tourism.

However, even if in Italy, people can find the best conditions for recognizing such actions absolutely essential to get the most value from cultural and historical connections that exist among many evidences of the peculiar heritage of each region, which encounters many difficulties. These are mainly due, as well as the size often contained of the widespread hotels and the potential involvement of organizations in public ownership (for example, civic museums), to the high costs of conflict determined by the divergent assessments of the distribution of costs and benefits and threats real or alleged with respect to the role of each.

The condition of the investigated hotels and their potential for development can be exemplified by reference to the matrix developed by Weaver (2011). The model aims to define (depending on the level of regulation of tourism development and the intensity of the incoming flows) the positioning of territories object of tourist destinations (characters and level of sustainability of tourism development) and monitor and manage its evolutionary path, defining policies consistent with the starting conditions.

The realities of Umbria, with low levels of both dimensions, correspond to a circumstantial model of tourism development (CAT). The desired increase in regulation will allow them to evolve from this configuration, typical of the exploration phase of the life cycle of a tourist destination, to an alternative approved tourism (DAT). The increase in flows that can be expected from increased regulation would then bring these realities to the optimal configuration of sustainable mass tourism (Figure 5). It should, however, be pointed out that, referring to forms of widespread hospitality and its territories, the term "mass" refers to the intensity of tourist flows which saturates the accommodation capacity of the hotel and weigh considerably on the territory one, despite being modest than the one found in destinations properly of mass. Only under these 
conditions, in fact, will widespread hotels and their respective territories be able to count on a volume of demand adequate to achieve a level of economic efficiency that ensures the sustainability of development, while remaining non-ordinary destinations, little gems to be discovered, enabling visitors to dip themselves in the atmosphere of the place and to experience unique experiences.

A flow of tourists, therefore, of a size does not affect the features to which they bind the main determinants of choice of their main cluster of users.

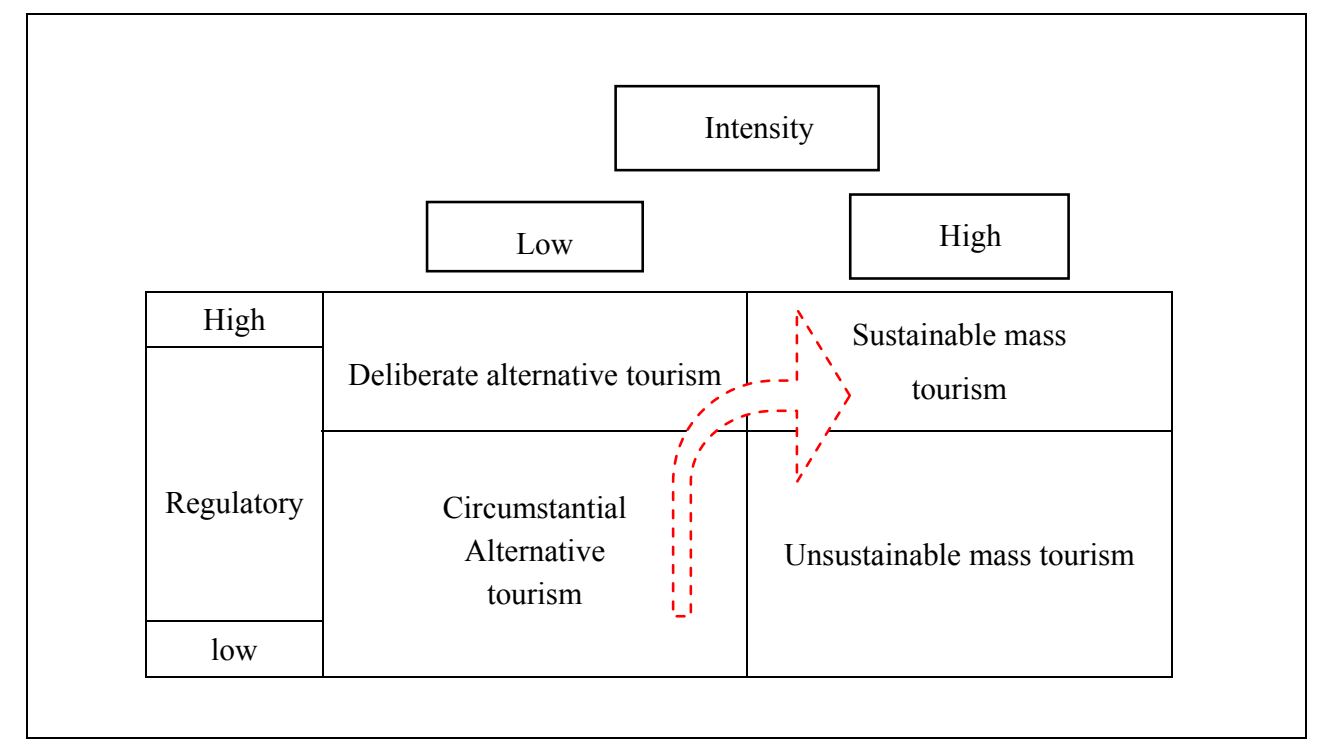

Figure 5. Evolution of widespread hotels in Weaver matrix (2011).

\section{Conclusions}

This paper's aims is to contribute to the studies flourished in the last decade on the widespread hotels and offer guidance both to entrepreneurs in this receptive sector for local policy makers to improve their performance.

Therefore, in the light of the new characters of tourism demand and in particular for the experiential and cultural trends and the paradigm of sustainability, it illustrates the potential of this innovative format to intercept the potential demand and satisfy the actual one, as well as support the sustainable development of the territories. In fact, the widespread hotels, located in small areas whose cultural value is given by the systemic set of the many elements that testify the common conditions of existence, are episodes of a story that unfolds in the territory from which the uninterrupted museum landscape is discovered. The competitive advantage is Italian. In addition, they help to distribute the flow of tourists throughout the year and in peripheral areas rather than evolved and mass contexts, balancing the economic fallout of accommodation with the protection of irreproducible resources (material and immaterial) of the territory. Such a managerial orientation, focusing on local roots and sustainability, benefits the quality of life of individuals and community, differentiates the offer, and allows achieving competitive advantages maintainable in the long run.

In addition to this, the research, updating the framework of the Italian widespread hotels and studying in deep the case of Umbria, a region particularly dynamic in terms of cultural heritage, artistic flows, and widespread hospitality, offers the opportunity to highlight, in agreement with the findings from other studies on widespread hotels, the urgency to enter into significant innovations that make it possible to create the entire 
possible value, starting with the strengthening of regional regulation. In addition to the essential strengthening of regulations, it would be very useful to enter the widespread hotels in associations of various nature that can direct and support them, as well as in tourist circuits, presenting them as an accommodation solution between tradition and innovation. It should also increase investments in the widespread hospitality sector and differentiate their offerings, by stimulating also the participation of hotel chains to a major professionalism.

The paper, dealing with an issue still not much investigated for its recent spread and in relation to which there are no official and quantitative surveys of reference, arises itself as an exploratory study and acts as a motivation for future investigations. Authors can then make up for the limitations of the presented study by enlarging the number of considered cases, extending the empirical analysis to other subjects and geographical areas, deepening the virtuous relationship between this form of hospitality and the pursuit of sustainable goals by individuals that realize it, trying to measure the value actually created by these enterprises for themselves and for the country, as well as proposing models to establish long-lasting partnerships among actors in the tourism industry, between the latter and the cultural one and even with the others of the territory (from wine and food to crafts, etc.).

\section{References}

Ahn, B., Lee, B., \& Shafer, C. S. (2002). Operationalizing sustainability in regional tourism planning: An application of the limits of acceptable change framework. Tourism Management, 23(1), 1-15.

Altili, P. (2010). I prodotti agroalimentari tradizionali come beni culturali. Economia della Cultura, 1, 34-46.

Ashworth, G., \& Larkham, P. (2013). Building a new heritage (RLE Tourism). London: Routledge.

Atchison, C., MacLeod, N. E., \& Shaw, S. J. (2014). Leisure and tourism landscapes: Social and cultural geographies. London: Routledge.

Baker, J., \& Cameron, E. (2008). Critical success factors in destination marketing. Tourism and Hospitality Research, 8(2), 79-97.

Beritelli, P. (2011). Cooperation among prominent actors in a tourist destination. Annals of Tourism Research, 38, 607-629.

Boisen, M., Terlouw, T., \& Van Gorp, B. (2011). The selective nature of place branding and the layering of spatial identities. Journal of Place Management and Development, 4(2), 135-147.

Boniface, P. (2013). Managing quality cultural tourism. London: Routledge.

Bramwell, B., \& Lane, B. (2011). Critical research on the governance of tourism and sustainability. Journal of Sustainable Tourism, 19(4-5), 411-421.

Buckley, R. (2012). Sustainable tourism: Research and reality. Annals of Tourism Research, 39(2), 528-546.

Burton, I. (1987). Report on reports: Our common future: The world commission on environment and development. Environment: Science and Policy for Sustainable Development, 29(5), 25-29.

Carù, A., \& Cova, B. (2007). Consuming experiences. London: Routledge.

Crang, M. (2014). Cultural geographies of tourism. In A. A. Lew, C. M. Hall, \& A. M. Williams (Eds.), The Wiley Blackwell companion to tourism (pp. 74-84). Oxford: John Wiley \& Sons.

De Carlo, M., \& Dubini, P. (2010). Integrating heritage management and tourism at Italian cultural destinations. International Journal of Arts Management, 12(2), 30-43.

Denicolai, S., Cioccarelli, G., \& Zucchella, A. (2010). Resource-based local development and networked core-competencies for tourism excellence. Tourism Management, 31(2), 272-278.

Droli, M., \& Dall'ara, G. (2012). Ripartire dalla bellezza. Gestione e marketing delle opportunità d'innovazione nell'albergo diffuso nei centri storici e nelle aree rurali. Padova: Cleup.

European Commission. (2004). European innovation scoreboard. Comparative analysis of innovation performance (Commission $\begin{array}{lllll}\text { Staff Working } & \text { Paper, } & \text { SEC(2004) } & \text { 1475). } & \text { Retrieved }\end{array}$ http://cordis.europa.eu/documents/documentlibrary/69884631EN6.pdf

Ferrari, S., \& Veltri, A. R. (2008). L'approccio esperienziale nell'offerta dei beni culturali. Il caso di Emozioni da Museo. Finanza, Marketing e Produzione, 4, 66-95. 
Franch, M., Martini, U., Buffa, F., \& Parisi, G. (2008). 4L tourism (landscape, leisure, learning and limit): Responding to new motivations and expectations of tourists to improve the competitiveness of Alpine destinations in a sustainable way. Tourism Review, 65(1). 4-14.

Girard, L. F., \& Nijkamp, P. (2009). Cultural tourism and sustainable local development. Farnham: Ashgate.

Golinelli, G. M. (2012). Patrimonio culturale e creazione di valore. Verso nuovi percorsi. Padova: Cedam.

Gössling, S., Hall, C. M., \& Weaver, D. B. (2009). Sustainable tourism futures: Perspectives on systems, restructuring and innovations. New York: Routledge.

Kavaratzis, M., \& Hatch, M. J. (2013). The dynamics of place brands: an identity-based approach to place branding theory. Marketing Theory, 13(1), 69-86.

Mazanec, J. A., Woeber, K., \& Zins, A. H. (2007). Tourism destination competitiveness: From definition to explanation? Journal of Travel Research, 46(1), 86-95.

Mckercher, B., \& Du Cros, H. (2002). Cultural tourism. The partnership between tourism and cultural heritage management. London: Routledge.

Montella, M. (2012). Il cibo come bene culturale. In G. M. Golinelli (Ed.), Patrimonio culturale e creazione di valore. Verso nuovi percorsi (pp. 27-36). Padova: Cedam.

Montella, M. M. (2012). Marketing del cultural heritage territoriale e musei d'impresa. Un caso di analisi. Mercati e Competitività, 4, 33-51.

Murphy, M. (2011). The towns Italy forgot. Retrieved from http://travel.nationalgeographic.com/travel/italy-hotels-traveler/

National Tourism Observatory. (2013). Panoramica sul turismo culturale. Roma: National Tourism Observatory.

Organization for Economic Cooperation and Development. (2009). The impact of culture on tourism. Paris: Organization for Economic Cooperation and Development.

Paniccia, P., Silvestrelli, P., Montella, M. M., Rozera, C., \& Valeri, M. (2013). Innovare nell'ottica della sostenibilità. L'esempio dell' "albergo diffuso": un progetto di valorizzazione per il territorio. In M. Franch, \& U. Martini (Eds.), GSA AIDEA. Bologna, IT: Il Mulino.

Quattrociocchi, B., Faggioni, F., \& Montella, M. M. (2012). Protection, preservation and enhancement, three main aspects of the Italian cultural heritage. In A. Morvillo (Ed.), Advances in tourism studies: In memory of Clara Stefania Petrillo (pp. 381-408). Milano: McGraw Hill.

Raagmaa, G. (2002). Regional identity in regional development and planning. European Planning Studies, 10(1), 55-76.

Ringer, G. (2013). Destinations: Cultural landscapes of tourism. London: Routledge.

Santagata, W. (2006). Cultural districts and their role in economic development. In V. Ginsbourg, \& D. Throsby (Eds.), Handbook on the economics of art and culture. Amsterdam: Elsevier Science.

Scuttari, A., Lucia, M. D., \& Martini, U. (2013). Integrated planning for sustainable tourism and mobility-A tourism traffic analysis in Italy's South Tyrol region. Journal of Sustainable Tourism, 21(4), 614-637.

Silvestrelli, P. (2012). Tourism development through heritage enhancement and hospitality innovation. International Journal of Globalisation and Small Business, 5(1/2), 20-33.

Smith, M., \& Richards, G. (2013). The Routledge handbook of cultural tourism. London: Routledge.

Throsby, D. (2005). Economia e cultura. Bologna: Il Mulino.

Waligo, V. M., Clarke, J., \& Hawkins, R. (2013). Implementing sustainable tourism: A multi-stakeholder involvement management framework. Tourism Management, 36, 342-353.

Weaver, D. B. (2011). Organic, incremental and induced paths to sustainable mass tourism convergence. Tourism Management, 33(5), 1030-1037.

Williams, G. (2010). Saving towns by filling rooms in Italy. The New York Times. Retrieved from http://travel.nytimes.com/2010/05/23/travel/23journeys.html?pagewanted=all 